\title{
The Labor Market Value of Taste: An Experimental Study of Class Bias in U.S. Employment
}

\author{
Kyla Thomas
}

University of Southern California

Abstract: This article investigates cultural forms of class bias in the middle-income U.S. labor market. Results from an audit study of employment discrimination in four U.S. cities reveal that cultural signals of class, when included in résumés, have a systematic effect on the callback rates of women applying to customer-facing jobs. For these women, displays of highbrow taste-the cultural signals of a higher-class background-generate significantly higher rates of employer callback than displays of lowbrow taste-the cultural signals of a lower-class background. Meanwhile, cultural signals of class have no systematic effect on the callback rates of male and/or non-customer-facing job applicants. Results from a survey-experimental study of 1,428 U.S. hiring managers suggest that these differing patterns of employer callback may be explained by the positive effect of higher-class cultural signals on perceptions of polish and competence and their negative effect on perceptions of warmth.

Keywords: culture; social class; social stratification; discrimination; hiring

Citation: Thomas, Kyla. 2018. "The Labor Market Value of Taste: An Experimental Study of Class Bias in U.S. Employment." Sociological Science 5: 562-595.

Received: November 15, 2017

Accepted: July 15, 2018

Published: September 12, 2018

Editor(s): Jesper Sørensen, Kim Weeden

DOI: $10.15195 /$ v5.a24

Copyright: (C) 2018 The Author(s). This open-access article has been published under a Creative Commons Attribution License, which allows unrestricted use, distribution and reproduction, in any form, as long as the original author and source have been credited. (C) (i)
SOCIAL class origin is one of the most powerful predictors of economic success in $\mathcal{S}$ the United States today. Studies estimate that 40 percent of children born into the bottom quintile of the occupational and income distribution will remain there as adults, and levels of mobility are found to be even lower among women than men (Beller and Hout 2006; Urahn et al. 2012). To account for inequalities in occupational attainment and income, scholars commonly cite class-based differences in the human and social capital men and women bring to the labor market. Yet, a series of new studies suggests these disparities may also be attributable to the hidden forms of class bias workers encounter as they attempt to enter the labor market.

In elite occupations, research shows that employers often favor job applicants who signal a higher-class background in their résumés, largely because they perceive them to be a better fit for the culture of their high-status firms (Rivera 2012; Rivera and Tilcsik 2016). The central inquiry of this article is whether this fondness for the class-advantaged applicant observed in elite labor markets reflects a more pervasive class bias among employers, one that trickles down to less prestigious labor markets as well. Is class-based discrimination primarily a mechanism of elite social closure, or is it a more pervasive labor market phenomenon?

To address this question, I examine the impact that cultural signals of social class - namely, résumé-based indicators of highbrow and lowbrow cultural tastehave on the evaluation and selection of American workers for middle-income jobs. It is well established that people's cultural practices and tastes are patterned by, and widely perceived to reflect (Bourdieu 1984; Coleman, Rainwater, and McClelland 1978; Lewis 2008; Lizardo and Skiles 2016; Yodanis 2006), their social class backgrounds. On average, a taste for traditionally highbrow culture, such as classical 
music and fine art, is associated with a higher-class position in the United States than a taste for traditionally lowbrow culture, such as heavy metal music and commercial art (DiMaggio and Mukhtar 2004; Mohr and DiMaggio 1995; Peterson and Simkus 1992; ter Bogt et al. 2011; van Eijck 1997). Research also shows that in educational contexts, greater opportunities and rewards are often afforded to individuals with highbrow cultural traits, such as a penchant for theater or jazz, advantaging upper-middle-class children with the parental resources to cultivate such traits at home (Aschaffenburg and Maas 1997; DiMaggio 1982a). The question I explore below is whether these class-based advantages extend beyond the walls of the classroom and into the middle-income labor market.

According to prior research, two key factors may influence whether and how employers use cultural signals of class to evaluate and select middle-income workers. The first factor that may moderate the effect of cultural signals of class on hiring outcomes is the gender of a job applicant. Class-based standards of cultural participation and taste tend to be more stringent for females than males, as cultural consumption has historically been viewed as the "separate sphere" of women (Christin 2012; Collins 1988, 1992). It follows from this literature that cultural signals of class may have a stronger effect on the evaluation and selection of women than men. I refer to this as the Gender Role Hypothesis.

The second factor that may moderate the effect of cultural signals of class on labor market outcomes is the hiring position itself. Collins and colleagues have long argued that class-based cultural standards tend to be more stringent in customerfacing job contexts than in non-customer-facing job contexts (Collins 1971, 1974; Williams and Connell 2010). Consequently, the effect of cultural signals of class on hiring outcomes may vary not only according to the gender of a job applicant but also according to the customer orientation of the hiring position at stake. I refer to this as the Conditional Gender Role Hypothesis.

To test the above hypotheses and measure the causal effect that cultural signals of class have in nonelite hiring contexts, I conducted an audit study of employment discrimination in four major U.S. cities. For five months, I performed a series of correspondence tests to measure the effect of cultural signals of class on employer callback rates for men and women applying to four of the most common jobs in the United States: customer service, sales, administrative, and clerical positions. To apply for these positions, I submitted two résumés, in randomized order, one day apart: one for an applicant with the cultural signals of a higher-class background (highbrow cultural tastes) and one for an applicant with the cultural signals of a lower-class background (lowbrow cultural tastes). Applicants signaled highbrow or lowbrow cultural tastes through the extraprofessional music, sports, and food activities they listed in their résumés.

I then tracked employers' responses to each résumé and analyzed how responses varied according to the gender of the job applicant and the customer orientation of the hiring positions. In support of the Conditional Gender Role Hypothesis, my results reveal that signals of cultural taste have a significant effect on the callback rates of women applying to customer-facing jobs. For these women, displays of highbrow taste lead to systematically higher rates of employer callback than 
displays of lowbrow taste. Meanwhile, signals of cultural taste have no significant effect on the callback rates of male and/or non-customer-facing job applicants.

What leads employers to discriminate on the basis of cultural taste? To address this question, I distributed a survey experiment to a national sample of 1,428 U.S. hiring managers. In the experiment, respondents were asked to evaluate two job applicants seeking a (customer-facing or non-customer-facing) position at a hotel. They were provided with two résumés, the same résumés used in the audit study, and they were asked to rate their likelihood of recommending each applicant for an interview. They were also asked to rate each applicant on a series of characteristics related to competence, warmth, and polish. On average, I find that hiring managers report a greater likelihood of interviewing applicants with highbrow cultural tastes, particularly when they are evaluating such applicants for customer-facing jobs. I also find that this preference for highbrow applicants is driven primarily by perceptions of polish and, secondarily, by perceptions of competence.

Overall, this study contributes to the sociological literature on class, culture, and labor market stratification by exposing a systematic form of class bias in the middle-income American labor market: employment discrimination on the basis of cultural signals of class. Additionally, this study highlights the highly gendered and customer-centric nature of this class bias and identifies a series of socialpsychological factors that may motivate this class bias in middle-income hiring contexts.

\section{Class Reproduction in the U.S. Labor Market}

Today, there are two leading approaches to studying class inequality at the hiring interface. The first comes from the status attainment literature, and the second comes from the employment discrimination literature. In the status attainment literature, access to human capital (education, experience, and skills) and social capital (connections to friends, acquaintances, and kin who can provide information about or access to good jobs) figure most prominently as the mechanisms through which inequalities in class origin are reproduced at the hiring interface (Farkas 1996; Granovetter 1974; Lin 1999). The weakness of these status attainment models, however, is their inattention to class-based discrimination-to the differential treatment workers receive regardless of the human or social capital they possess.

This has been rectified in the last decade by a growing experimental literature. In elite labor markets, research now shows that employers can be quite sensitive to the social class cues applicants include in their résumés. In her audit study of professional and managerial labor markets in the United Kingdom, for example, Jackson (2009) finds that job applicants with certain combinations of typically "upper-class" traits receive higher rates of callback from employers, though the callbacks are not systematically more positive. Likewise, a recent audit study of U.S. law firms (Rivera and Tilcsik 2016) provides compelling evidence that employers respond more favorably to male applicants who signal a higher-class background in their résumés. Based on these studies, we may conclude that signals of a higher-class background are likely to advantage certain workers seeking access to high-status, high-paying jobs. 
What this means for the majority of Americans entering nonelite labor markets, however, is unclear. If class-based discrimination is primarily a mechanism of elite social closure, then it is unlikely to endure in nonelite labor markets. However, if class is a more fundamental category of perception and evaluation, then signals of cultural taste, to the extent that they act as signals of social class in the United States, should influence employer decision-making in nonelite labor markets.

\section{Conceptualizing Social Class in the United States}

Adapting experimental methods pioneered in the study of race and gender discrimination to the study of social class discrimination presents unique theoretical and methodological challenges. As a category of analysis, class is widely debated, and sociologists still lack a common conceptualization and measure (for reviews, see DiMaggio 2012; Wright 2005). One of the most famous proponents of class analysis, Karl Marx, defined class as one's relationship to the means of production (Marx [1867] 1978). Current-day approaches that build on Marxian theory conceptualize class as being rooted in job conditions, such as autonomy, authority, and control (Wright 2005; Wright et al. 1982). Others define class in terms of market relations, including those rooted in property ownership, authority relations, occupation, and education (Erikson and Goldthorpe 1992; Grusky and Sorensen 1998; Treiman 1977). This conceptualization of class builds on the work of Weber ([1922] 1958), who theorized class situation as one's position in various markets for property, labor, and commodities (DiMaggio 2012; Wright 2005).

Marxian and Weberian approaches to class analysis differ in many respects. However, a notable commonality between them is their treatment of social class as a structurally derived analytic category rooted solely in economic conditions. Often, the study of class as an analytic category has been divorced from the study of class, as it is socially and culturally constructed in everyday life. The primary aim of this study, however, is to understand how perceptions of social class inform the hiring behaviors of American employers. And so, our starting point must be a conceptualization of social class that is not only structurally grounded but also socially meaningful.

Here, the class model developed by Pierre Bourdieu $(1984 ; 1990)$ proves quite useful, as Bourdieu's primary aim was to overcome the divide between structuralist and constructivist conceptualizations of social class. Like Marx and Weber, Bourdieu defines social class in structural terms as a relationship to income-generating resources (Wright 2005) or capital (Bourdieu 1984). However, he departs from Marx and Weber by incorporating into his class model the cultural mechanisms through which structurally defined class positions are made socially observable and consequential.

Of particular importance to this study is Bourdieu's identification of status culture, defined here as "distinct cultural traits, tastes, and styles" (DiMaggio 1982a:189), as being central to the symbolic construction and reproduction of class in everyday life. According to Bourdieu, "... a class is defined as much by its being perceived as by its being, by its consumption . . . as much as by its position in the relations of production (even if it is true that the latter governs the former)" 
(Bourdieu 1984:483). Thus, although Bourdieu recognizes class as analytically distinct from status culture, he posits that in practice, class is symbolically defined and made socially meaningful through status-cultural signals, such as consumption, making status culture a key mechanism of class expression and differentiation in social life.

Building on Bourdieu's work, class analysts in the United Kingdom have advocated for a multidimensional conceptualization of class as a relationship to capital generated, in part, through status-culture signaling (Devine 1998, 2004; Savage et al. 2013). Savage et al. (2013:223) assert that "classes are not merely economic phenomena but are also profoundly concerned with forms of social reproduction and cultural distinction." Likewise, for the purposes of this study, I conceptualize social class as a relationship to income-generating resources that both patterns statusculture signaling and is symbolically defined and expressed through status-culture signaling.

\section{Cultural Signals of Class in the United States}

In the United States, this conceptualization of status-culture signaling as a mechanism of class signaling is bolstered by a rich literature on subjective class identification. Studies show that Americans tend to perceive class as gradational and often draw on indicators of market position, such as income, occupation, and education, to identify gradations of social class (Coleman et al. 1978; Hout 2008). Such information, however, is often not immediately available to individuals in everyday social interactions, so people tend to rely on other signals-cultural signals-to perceive and evaluate the class standing of others (Bourdieu 1984; Coleman et al. 1978; Yodanis 2006).

What status-culture signals may be conceptualized as signals of social class in the United States? For decades, the cultural mechanisms through which class is instantiated in social life have been of central concern to sociologists of culture (DiMaggio 2012). Within this literature, scholars cite interactional style, accent, speech cadence, style of dress, parenting strategies, moral values, bodily comportment, and cultural taste as key markers of class position (Bourdieu 1984; DiMaggio and Useem 1978; Lamont 1992; Lamont and Lareau 1988; Lareau 2003; Weininger, Lareau, and Conley 2015; Yodanis 2006).

Cultural tastes are the focus of this article and include preferences for music, art, food, and leisure (Bourdieu 1984; Veblen [1899] 1967). According to prior studies, measures of social class tend to be moderately predictive of the status level of an individual's cultural tastes. In particular, research shows that a taste for traditionally high-status, or highbrow, culture is associated with a higher-class background than a taste for traditionally low-status, or lowbrow, culture. ${ }^{1}$ For example, incomegenerating resources such as educational attainment and occupational prestige are positively associated with a taste for classical music, opera, and jazz and negatively associated with a taste for country and gospel music (Bryson 1996; DiMaggio and Mukhtar 2004; Peterson and Simkus 1992). Furthermore, researchers find that individuals' cultural preferences are heavily influenced by their parental backgrounds. Children from class-advantaged backgrounds are more likely to develop tradition- 
ally highbrow cultural tastes than children from disadvantaged class backgrounds (ter Bogt et al. 2011; Mohr and DiMaggio 1995; van Eijck 1997).

Two decades ago, a growing pattern of omnivorous cultural taste was detected among American elites (Peterson and Kern 1996; Peterson and Simkus 1992), leading some to conclude that class-based differences in taste for highbrow and lowbrow culture are waning. However, the work of Rossman and Peterson (2015) suggests that the rise of omnivorousness as a class marker may have been short lived. Since its peak in the 1990s, the prevalence of omnivorous cultural consumption has declined substantially and returned to pre-1990s levels. Additionally, more recent studies have shown that although elites may be more tolerant of diverse cultural forms, they are still singular in their familiarity with and taste for exclusionary, and often traditionally highbrow, cultural forms (Bryson 1996; Holt 1997; Johnston and Baumann 2007; Ollivier 2008; Warde, Wright, and Gayo-Cal 2007).

Recent studies have also shown that cultural taste is not only patterned by social class but widely perceived to be an indicator of social class in the United States. According to the work of both Lewis (2008) and Lizardo and Skiles (2016), Americans tend to associate traditionally highbrow cultural tastes with a higher-class background and traditionally lowbrow cultural tastes with a lower-class background. Thus, for the purposes of this study, I conceptualize a taste for highbrow culture as the cultural signal of a higher-class background and a taste for lowbrow culture as the cultural signal of a lower-class background. The question I consider next is whether signals of highbrow and lowbrow cultural taste are consequential for job applicants in nonelite hiring contexts. I identify job type and applicant gender as two factors that may moderate the effect of cultural signals of class on labor market outcomes, and I identify perceptions of competence, polish, and warmth as three factors that may mediate their effect on hiring evaluations.

\section{Theories and Hypotheses}

\section{Moderating Factors}

A popular theory in the sociology of culture is that institutions generally privilege the highbrow cultural tastes of elites over the lowbrow cultural tastes of nonelites because a class-based cultural hierarchy exists in which the cultural tastes of elites are perceived as signals of greater legitimacy and social worth (Bourdieu 1973, 1984). Although this theory of class-based cultural exclusion was developed according to observations of late-1960s Paris, evidence of a similar pattern of exclusion has been found in the United States, primarily in the context of education (Aschaffenburg and Maas 1997; DiMaggio 1982a; DiMaggio and Mohr 1985; Lizardo 2006a). This has led some to conclude that highbrow cultural taste constitutes a form of capital in the United States (DiMaggio 1982a; DiMaggio and Mohr 1985). Applied to the context of hiring, this literature suggests that American employers will value signals of highbrow cultural taste over signals of lowbrow cultural taste and systematically reward the job applicants who display the former.

More recent research, however, has shown that cultural tastes carry not only class associations but gendered expectations, reflected in men's and women's di- 
vergent patterns of high-status cultural participation (Christin 2012; Collins 1992; Lizardo 2006b). Women are much more likely than men to participate in highbrow cultural activities, such as reading fiction (Douglas 1977; Tepper 2000) and attending concerts, arts museums, plays, and the opera (DiMaggio 1982a; DiMaggio and Mohr 1985; Dumais 2002). Moreover, Lizardo (2006b) finds that this gender gap in cultural participation is largely characteristic of those in the labor force and is greatest between men and women working in market-oriented occupations.

How do we account for this gender gap? According to Christin (2012), it is due largely to gendered expectations around arts socialization. American parents are significantly more likely to enroll their daughters in music and art history lessons than their sons due to "broad cultural scripts about appropriate gender roles." The consumption and circulation of highbrow culture has historically been viewed as the "separate sphere" or "labor" of women and has played an important role in the cultural reproduction of social class in middle-class households (Christin 2012). In their seminal study of the social class structure in Kansas City, for example, Coleman and Neugarten (1971) find that a strong predictor of a man's social class is the status-cultural participation of his wife. Similarly, according to Upright (2004), one of the most reliable predictors of a man's attendance at arts events is the arts participation of his wife.

DiMaggio (1982a) also finds that in high school, the correlation between highbrow cultural participation and family background as well as the intercorrelations among highbrow cultural measures are much stronger for females than for males. These findings suggest that the class-based cultural interests and activities of women are more coherent and socially prescribed than those of men. It also suggests that displays of highbrow cultural participation and taste may play a more important role in the reproduction of class advantage among women. Thus, I hypothesize that in the middle-income labor market, signals of cultural taste will have a more positive and systematic effect on the outcomes of women than men.

Hypothesis 1 (Gender Role Hypothesis): Signals of highbrow, versus lowbrow, taste will have a more positive effect on the labor market outcomes of women than men.

That said, the cultural standards applied to female versus male workers may also vary according to the hiring position at stake. Collins $(1971,1974)$ asserts that in jobs that require heavy interaction with customers, employers are particularly concerned with establishing normative control over employees and, as a result, seek out workers with the cultural markers of a higher-class background. As Williams and Connell (2010) write, when "looking good" and "sounding right" for customers are a source of company revenue, employers desire customer-facing workers with typically upper-middle-class traits. Highbrow cultural displays are likely to be rewarded in customer-facing hiring contexts more so than in non-customer-facing hiring contexts.

Research also suggests that this preference for customer-facing workers with higher-class traits may be more consequential for female workers than male workers (Collins 1971). As the literature on "emotion work" has shown, displays of polish, friendliness, and deference in interaction are not only an unstated job requirement in 
customer-facing jobs but also a form of labor more commonly expected of customerfacing women than customer-facing men (Hochschild 1979; Macdonald and Sirianni 1996). Consequently, I hypothesize that the highbrow cultural displays of women, more so than those of men, are likely rewarded by employers in customer-facing contexts more so than those in non-customer-facing contexts.

Hypothesis 2 (Conditional Gender Role Hypothesis): For customer-facings jobs, more so than non-customer-facing jobs, signals of highbrow, versus lowbrow, taste will have a more positive effect on the labor market outcomes of women than men.

\section{Mediating Factors}

What would lead employers in a nonelite labor market to favor applicants with highbrow cultural tastes over those with lowbrow cultural tastes? In his work on education, Bourdieu $(1973,1984)$ has famously asserted that individuals' cultural practices and tastes shape their educational outcomes because they systematically bias the levels of competence or merit teachers and educational gatekeepers attribute to students. Students with higher-class cultural traits are favored in elite schools, Bourdieu posits, because their cultural traits are perceived as a form of social and technical competence. Likewise, evaluations of competence, defined here as one's ability to complete a task successfully (Cuddy, Fiske, and Glick 2007; Fiske et al. 2002), are found to be an important basis for employer decision-making at the point of hire. Studies show that it is often on the basis of perceived competence or skill that employers report a general preference for those with high-status characteristics, including workers who are white, male, unmarried, and have a standard employment history (Correll, Benard, and Paik 2007; Moss and Tilly 2001; Pedulla 2016). Building on this literature, I will explore the hypothesis that attributions of competence mediate the effect of signals of cultural taste on the hiring evaluations of employers.

\section{Hypothesis 3 (Competence Hypothesis): Signals of cultural taste affect hiring} evaluations because they influence perceptions of competence.

It is important to note that in their work on elite law firms, Rivera and Tilcsik (2016) find that signals of class have no significant effect on perceptions of an applicant's competence. However, this result may be explained by the exceptionally high quality of the résumés Rivera and Tilcsik were presenting to employers. In Rivera and Tilcsik's survey experiment, applicants' class backgrounds are signaled in résumés alongside elite educational and occupational credentials—strong signals of merit that likely muted many differences in perceived competence between job applicants.

Recent studies also suggest that employers aim to hire workers who are not simply able to complete tasks but who communicate and present themselves in a style deemed socially appropriate and professional (Kirschenman and Neckerman 1991; Moss and Tilly 2001; Williams and Connell 2010). Rivera and Tilcsik (2016) refer to these workers as workers with polish-workers who display an uppermiddle-class style of self-presentation and interaction. In Bourdieusian theory, 
polish, or comportment, is conceptualized as a key form of capital. Like cultural background and taste, it is a means through which class advantages are expressed and made socially consequential in interactions and institutions (Bourdieu 1984, 1986).

In middle-class and/or customer-facing job contexts, studies suggest that employers often seek out workers with upper-middle-class backgrounds and traits because they expect them to have a style of speaking, acting, and looking that is appropriate and professional for a white-collar setting (Collins 1971; Kirschenman and Neckerman 1991; Moss and Tilly 2001; Williams and Connell 2010). Within the context of this study, such concern for polish may drive employers to favor applicants with highbrow cultural tastes, especially for entry into customer-facing jobs, in which standards of polish are theorized to be high.

Hypothesis 4 (Polish Hypothesis): Signals of cultural taste affect hiring evaluations because they influence perceptions of polish.

Alternatively, signals of cultural taste may influence the hiring evaluations of employers through their effect on perceptions of warmth. In the social psychological literature, warmth refers to a series of traits (including sincerity and trustworthiness) that reflect one's likability and intentions (Cuddy et al. 2007; Fiske et al. 2002). Rivera's study of cultural matching in hiring suggests that employers seek out workers they connect with personally and perceive to be likable, workers whose personalities they believe are well suited for their firm (Rivera 2011, 2012, 2015). Often, these perceptions of likability are intertwined with perceptions of class and culture. According to Rivera $(2012,2015)$, hiring managers in elite professional service firms tend to attribute greater likability to job candidates with higher-class cultural backgrounds and traits.

Whether these elite cultural traits are perceived as signals of likability, or warmth, in less prestigious contexts is unclear. Employers in a nonelite labor market may instead feel an affinity for job applicants with more mainstream, nonelite cultural traits and favor them at higher rates. In fact, recent work by Hahl and Zuckerman (2014) indicate that signals of lowbrow taste have a positive effect on perceptions of a quality related to warmth: authenticity.

Hypothesis 5 (Warmth Hypothesis): Signals of cultural taste affect hiring evaluations because they influence perceptions of warmth.

\section{Data and Methods}

To test the above hypotheses and measure the causal effect that cultural signals of class have on hiring evaluations and labor market outcomes, I first conducted an audit study of employment discrimination in four U.S. cities. For five months, I performed a series of correspondence tests to measure the effect that signals of highbrow and lowbrow cultural taste have, when included in résumés, on employer callback rates among men and women applying to customer-facing and non-customer-facing jobs. 


\section{Sample}

In total, I submitted 2,096 résumés and cover letters in response to 1,048 job openings. All résumés included an active Gmail account and Google Voice account so that I could track employers' responses to the résumés and measure rates of callback. For all résumés submitted, the average rate of callback was 11.5 percent.

\section{Experimental Design}

The job openings to which I submitted applications were for either customerfacing or non-customer-facing jobs. Summary statistics for the number of résumés submitted to each job category are shown in Table 1.

In response to each customer-facing or non-customer-facing job opening, I submitted two résumés one day apart: one résumé with indicators of highbrow cultural taste and one résumé with indicators of lowbrow cultural taste. The order in which these two résumés were submitted was randomized and counterbalanced. Additionally, both résumés signaled the same randomly assigned applicant gender: male or female. If the gender was male, both résumés included randomly assigned, stereotypically male applicant names; if the gender was female, both résumés included randomly assigned, stereotypically female applicant names.

Thus, the design of the audit study was a mixed-factorial design, as it included both within- and between-subjects sources of variation. The within-subjects source of variation was applicant cultural taste, as each study subject (or prospective employer) received two résumés that differed in their signals of cultural taste. The between-subjects sources of variation were applicant gender and job type, as these characteristics varied between résumé pairs and the employers to whom they were submitted. This mixed-factorial experimental design is outlined in greater detail in the online supplement.

\section{Job Type Measure}

To vary the customer orientation of the job and identify openings for customerfacing versus non-customer-facing jobs, I used a web crawler that collected information for all jobs posted over a 15- to 30-day period. To search for customer-facing positions, I used the following key words: "customer service" and "sales." To search non-customer-facing positions, I used the following key words: "administrative assistant" and "clerk." According to the Bureau of Labor Statistics, customer service, sales, administrative, and clerical jobs are four of the most common occupations in the United States.

After conducting these online searches, I reviewed the collection of openings generated by the web crawler to confirm that the applicants had the appropriate credentials and experience and to ensure that the positions were correctly classified as "customer-facing" or "non-customer-facing." In cases in which a job title spanned both customer-facing and non-customer-facing categories, I classified the job based on the primary responsibilities outlined in the job description. When the primary responsibilities spanned both categories, greater weight was given to the customer-facing responsibilities due to my hypothesis that employers would 
Table 1: Sampled job openings by job type and applicant gender.

\begin{tabular}{lccr}
\hline & Non-Customer-Facing Jobs & Customer-Facing Jobs & Total \\
\hline Male Applicants & 190 & 343 & 533 \\
Female Applicants & 191 & 324 & 515 \\
Total & 381 & 667 & 1,048 \\
\hline
\end{tabular}

be more likely to discriminate on the basis of cultural signals of class in hiring for positions with significant customer interaction. The job was then classified accordingly. For more information regarding the classification of job openings, see the online supplement.

\section{Cultural Signals of Class}

Taste for highbrow or lowbrow culture was signaled through the undergraduate clubs and personal interests listed in each résumé. Undergraduate clubs were listed toward the end of the résumé under the headings "Leadership Activities" or "Community Involvement," and personal interests were listed at the bottom of the résumé under the headings "Personal Interests" or "Hobbies." Applicants' positions in these two clubs were either "bookkeeper" and "secretary" or "treasurer" and "registrar." Applicants provided near-identical descriptions of their participation in the undergraduate clubs.

To signal highbrow cultural taste in a résumé, I listed participation in an undergraduate classical music club and an undergraduate tennis league. I also listed the following personal interests at the bottom of the résumé: playing tennis, jazz festivals, and gourmet cooking. To signal lowbrow cultural taste in a résumé, I listed participation in an undergraduate country music club and an undergraduate bowling league. I also listed the following personal interests at the bottom of the résumé: bluegrass concerts, barbecuing, and going bowling. These signals of highbrow and lowbrow taste are outlined in Table 2.

Data from the 2012 Survey of Public Participation in the Arts confirm that a taste for classical music and tennis is associated with a higher-class position in the United States than a taste for country music and bowling. For example, playing tennis and listening to classical music and jazz are activities that are more common among college-educated Americans, whereas going bowling and listening to country music and bluegrass are activities that are more common among non-college-educated Americans. ${ }^{2}$ Additionally, a preference for classical music frequently co-occurs with a preference for jazz, and a preference for country music frequently co-occurs with a preference for bluegrass. ${ }^{3}$

To verify that these individual highbrow and lowbrow cultural tastes not only objectively reflect differences in class location but are socially perceived to do so, I conducted a series of exploratory surveys on Amazon.com's crowdsourcing platform, Mechanical Turk, in which I asked respondents to rate the social class of targets with varying preferences in music, sports, and food. Those who have examined the stereotypes associated with various musical subcultures in the United 
Table 2: Cultural signals of class.

\begin{tabular}{lcc}
\hline & $\begin{array}{c}\text { Lowbrow Taste } \\
\text { (Lower-Class Signal) }\end{array}$ & $\begin{array}{c}\text { Highbrow Taste } \\
\text { (Higher-Class Signal) }\end{array}$ \\
\hline Undergraduate Music Club & Country music club & Classical music club \\
Undergraduate Sports Club & Bowling league & Tennis league \\
Personal Interests & $\begin{array}{c}\text { Bluegrass concerts, } \\
\text { barbecuing, } \\
\text { going bowling }\end{array}$ & $\begin{array}{c}\text { Playing tennis, } \\
\text { jazz festivals, } \\
\text { gourmet cooking }\end{array}$ \\
\hline
\end{tabular}

States find that people do perceive differences in the class backgrounds of those who listen to traditionally highbrow or lowbrow musical genres (Lewis 2008; Lizardo and Skiles 2016). Likewise, my exploratory surveys confirm that people who like traditionally highbrow music, sports, and food are perceived to be of statistically significantly higher class, on average, than people who like traditionally lowbrow music, sports, and food. For example, a person who likes classical music and tennis tends to be classified as upper-middle class, whereas a person who likes country music and bowling tends to be classified as working class. The music, sports, and food preferences selected for the résumés are also those perceived to be most prevalent among white Americans.

To confirm that the combinations of highbrow and lowbrow cultural taste described in Table 2 are systematically perceived as signals of higher- and lower-class positions when included in résumés, I surveyed an additional 401 U.S. residents on Mechanical Turk. Each respondent was provided with a résumé with a male or female applicant gender and signals of highbrow or lowbrow cultural taste. Analyses of variance confirm that for both the male and female applicants, the differing combinations of taste have a statistically significant effect on perceptions of social class. Both applicants are perceived as being middle class, but respondents perceive applicants with highbrow cultural tastes as being closer to upper-middle class than applicants with lowbrow cultural tastes, who tend to be rated as being lower-middle class $(\mathrm{F}[1,399]=8.73 ; p<0.01)$. For more information regarding the results of the Mechanical Turk studies described here, see the online supplement.

\section{Résumé Design}

Applicant gender was signaled through the applicant names listed at the top of the résumés. To signal a male gender, applicants were assigned the names "Scott Ryan" or "Jack Miller." Within a résumé pair assigned a male applicant gender, one résumé included the name "Scott Ryan," and the other résumé included the name "Jack Miller." To signal a female gender, applicants were assigned the names "Hannah Ryan" or "Sarah Miller." Within a résumé pair assigned a female applicant gender, one résumé included the name "Hannah Ryan," and the other résumé included the name "Sarah Miller." According to a survey of 100 U.S. residents 
conducted on Mechanical Turk, the names Scott, Jack, Hannah, and Sarah are all perceived, on average, as being typically middle-class names. The last names I used were based on the last names that were identified as being stereotypically white in Bertrand and Mullainathan's (2004) study of racial discrimination in hiring.

Apart from these manipulations, each pair of résumés listed near-identical occupational histories and educational backgrounds. Two résumé templates were used. The occupational and educational details included in each template varied slightly to ensure that employers did not detect the experimental manipulation. Both templates listed Bachelor of Arts degrees from small and similarly ranked liberal arts colleges with high acceptance rates in Michigan or Ohio. They also listed approximately two years of employment experience as an administrative or office assistant at a catering company or ticket agency. A summary of the items listed in the résumé templates can be found in Figure 1. Beyond these items, the résumé templates varied moderately in their font, wording, and formatting. ${ }^{4}$

The assignment of a template to each résumé in a résumé pair was randomized. This guaranteed that the manipulation of the résumé template varied independently of the manipulation of cultural signals of class. Pilot studies conducted on Amazon.com's Mechanical Turk confirm that the two résumé templates did not differentially influence how job applicants were perceived or evaluated. I also interviewed seven senior-level managers about the résumés to ensure that the résumé templates were comparable, realistic, and conventional in their presentation.

\section{Results}

The results of this experiment were analyzed by using a logistic regression model with standard errors clustered by hiring firm. I first measure the effect of signals of cultural taste on an applicant's likelihood of receiving a positive callback. Positive callback refers to any voicemail and/or email response that included either a formal request for an interview or a more informal request to discuss the hiring position in greater depth. In my analysis, I then differentiate between callbacks that included a formal request for an interview-a strong indicator of employer interest—and callbacks that included an informal request to talk more-a weaker indicator of employer interest. Forty-seven percent of the positive callbacks received by applicants were a formal request for an interview; 53 percent were an informal request to talk more. I run separate models to measure the effect of signals of taste on the likelihood of each type of response with no callback as the reference category.

In Table 3, Models 1a, 2a, and 3a test the Gender Role Hypothesis (Hypothesis 1) by estimating the two-way interaction effect of cultural taste and applicant gender on callback outcomes. Models 1b, 2b, and 3b test the Conditional Gender Role Hypothesis (Hypothesis 2) by estimating the three-way interaction effect of cultural taste, applicant gender, and job type on callback outcomes. To interpret these interaction effects, I report the average marginal effect (AME) of cultural taste across the factors with which it was interacted in each logistic regression model. According to extensive literature, the statistical significance of interaction effects in nonlinear models is best interpreted through the calculation of average marginal 


\section{APPLICANT NAME}

Street address

Email address, phone number

\section{Experience [or Relevant Experience]}

- Catering company [or ticket agency], 2012 - present

- Office assistant [or administrative assistant]

\section{Education}

- Liberal arts college

- B.A. in Business Administration [or Business Economics], 2012

Leadership Activities [or Community Involvement]

- Undergraduate music club, 2010 - 2012 [or 2009 - 2011]

- Undergraduate sports club, 2009 - 2010 [or 2011 - 2012]

\section{Computer Skills}

- Microsoft Word, Excel, Access, PowerPoint, Outlook, Adobe, Mac OSX, Windows, QuickBooks

\section{Personal Interests [or Hobbies]}

\section{- Personal interests}

Figure 1: Résumé items. Cultural signals of class were embedded in the items listed in italics. B.A., Bachelor of Arts; Mac OSX, Macintosh Operating System X.

effects and cross-partial derivatives (Ai and Norton 2003; Norton, Wang, and Ai 2004).

In Table 3, I first measure whether the effect of cultural taste on an applicant's likelihood of receiving a positive callback varies according to applicant gender (Model 1a). The Gender Role Hypothesis predicts that the average marginal effect of highbrow, versus lowbrow, cultural taste will be positive for women and greater for women than men. As expected, I find that the average marginal effect of highbrow cultural taste on the likelihood of positive callback is positive among women (AME $=0.01$; not significant) and negative among men (AME $=-0.01$; not significant). These effects, however, are small in magnitude and nonsignificant, so the hypothesis receives no statistical support.

The Conditional Gender Role Hypothesis predicts that signals of cultural taste will systematically affect the outcomes of women in customer-facing contexts. I test this prediction by calculating the average marginal effect of cultural taste among men and women applying to customer-facing versus non-customer-facing jobs (Model 1b). As predicted, I find that the effect of highbrow, versus lowbrow, taste on women applying to customer-facing jobs is positive (AME $=0.03 ; p<0.10$ ). I also find that this effect is greater in magnitude than the effect of cultural taste in 
Table 3: Average marginal effect of signals of highbrow taste, interacted with job type and applicant gender, on callback outcomes.

\begin{tabular}{|c|c|c|c|c|c|}
\hline \multirow[b]{2}{*}{ Hiring Conditions } & \multicolumn{2}{|c|}{$\begin{array}{l}\text { Positive } \\
\text { Callback }\end{array}$} & \multicolumn{2}{|c|}{$\begin{array}{c}\text { Formal } \\
\text { Interview Request }\end{array}$} & \multirow{2}{*}{$\begin{array}{c}\text { Informal } \\
\text { Follow-up } \\
\text { Model }\end{array}$} \\
\hline & Model & Difference & Model & Difference & \\
\hline Gender Role Hypothesis & Model 1a & & Model 2a & & Model 3a \\
\hline Female Applicant & $\begin{array}{c}0.01 \\
(0.01)\end{array}$ & & $\begin{array}{r}0.02^{*} \\
(0.01)\end{array}$ & (reference) & $\begin{array}{c}-0.00 \\
(0.01)\end{array}$ \\
\hline Male Applicant & $\begin{array}{c}-0.01 \\
(0.01)\end{array}$ & & $\begin{array}{c}-0.01 \\
(0.01)\end{array}$ & $\begin{array}{r}0.03^{\dagger} \\
(0.01)\end{array}$ & $\begin{array}{c}-0.00 \\
(0.01)\end{array}$ \\
\hline Conditional Gender Role Hypothesis & Model 1b & & Model 2b & & Model 3b \\
\hline \multicolumn{6}{|l|}{ Female Applicant } \\
\hline -Customer-Facing Job & $\begin{array}{r}0.03^{*} \\
(0.02)\end{array}$ & (reference) & $\begin{array}{r}0.03^{+} \\
(0.01)\end{array}$ & (reference) & $\begin{array}{c}0.01 \\
(0.01)\end{array}$ \\
\hline -Non-Customer-Facing Job & $\begin{array}{c}-0.02 \\
(0.02)\end{array}$ & $\begin{array}{r}0.05^{*} \\
(0.03)\end{array}$ & $\begin{array}{c}-0.01 \\
(0.01)\end{array}$ & $\begin{array}{r}0.04^{\dagger} \\
(0.02)\end{array}$ & $\begin{array}{c}-0.01 \\
(0.01)\end{array}$ \\
\hline \multicolumn{6}{|l|}{ Male Applicant } \\
\hline -Customer-Facing Job & $\begin{array}{c}-0.01 \\
(0.01)\end{array}$ & $\begin{array}{r}0.05^{\dagger} \\
(0.03)\end{array}$ & $\begin{array}{c}-0.02 \\
(0.01)\end{array}$ & $\begin{array}{r}0.05^{\dagger} \\
(0.01)\end{array}$ & $\begin{array}{c}-0.00 \\
(0.02)\end{array}$ \\
\hline -Non-Customer-Facing Job & $\begin{array}{c}-0.01 \\
(0.01)\end{array}$ & $\begin{array}{r}0.04^{*} \\
(0.02)\end{array}$ & $\begin{array}{c}-0.01 \\
(0.01)\end{array}$ & $\begin{array}{r}0.04^{\dagger} \\
(0.01)\end{array}$ & $\begin{array}{c}-0.01 \\
(0.01)\end{array}$ \\
\hline
\end{tabular}

Notes: Standard errors (in parentheses) are clustered by hiring firm. Two-tailed tests were used for significance.

${ }^{*} p<0.10,{ }^{+} p<0.05$.

any other gender and job condition. That said, inflated standard errors suggest that there is considerable heterogeneity in these effects.

Models $2 \mathrm{a}$ and $2 \mathrm{~b}$ report the effect of cultural taste on an applicant's likelihood of receiving a formal request for an interview versus no callback. As predicted by the Gender Role Hypothesis (Model 2a), the coefficient measuring the effect of highbrow taste among women is positive, yet when I examine differences across hiring contexts (Model 2b), I find that this highbrow effect is only positive among women applying to customer-facing jobs (AME $=0.03 ; p<0.05)$. It is also notable that the coefficients in Model $2 \mathrm{~b}$ are similar in size to the coefficients in Model 1b. The primary difference between these two models is the size of the standard errors, which are smaller in Model $2 b$ than in Model $1 b$, and this is indicative of a more reliable set of effects.

A statistical test of the differences between the effects reported in Model 2b confirms that the effect of cultural taste on the relative odds of receiving an interview request is systematically larger among women applying for customer-facing jobs than it is in any other gender and job condition $(p<0.05)$, lending support to the Conditional Gender Role Hypothesis. That said, it is important to note that although this cultural effect is systematic and moves in a theoretically meaningful direction, 
its magnitude is relatively small-much smaller, for example, than the magnitude of the effect of signals of race on hiring outcomes (Bertrand and Mullainathan 2004; Gaddis 2014; Pager 2003; Pager, Western, and Bonikowski 2009). It is also smaller than the class effects observed among men in an elite labor market (Rivera and Tilcsik 2016).

Models $3 \mathrm{a}$ and $3 \mathrm{~b}$ measure the average marginal effect of cultural taste on an applicant's likelihood of receiving an informal follow-up from employers. In both models, the magnitude of the coefficients is close to zero across gender and job conditions, evidence that employers do not systematically discriminate on the basis of taste in their decision to follow-up informally with male and female applicants. I conclude that the effect of cultural taste on rates of positive callback is driven primarily by its effect on the likelihood that employers will express a strong interest in applicants and extend a formal interview request early in the application process.

How do the average marginal effects reported in Table 3 translate into actual rates of callback? Figure 2 presents the average rates of positive callback for men and women applying for customer- and non-customer-facing jobs across all four cities. One can see in this figure that among customer-facing job applicants, women with highbrow tastes receive a higher response rate (16.36 percent) than women with lowbrow tastes (13.27 percent), a difference in callback rates of approximately 20 percent. This suggests that for customer-facing job openings, a woman with highbrow cultural tastes would need to submit six résumés to receive a positive response from an employer, whereas a similarly qualified woman with lowbrow cultural tastes would need to submit eight résumés.

One can also see in Figure 2 that for customer-facing job openings, the rate of response for women with highbrow tastes is quite similar to that of men with lowbrow tastes. Thus, relative to male customer-facing job applicants, women are not so much advantaged by highbrow cultural signals as they are disadvantaged by lowbrow cultural signals. Furthermore, it is notable that the effect of these cultural signals among women applying to customer-facing jobs is similar in magnitude to the effect of college selectivity observed among white job applicants (Gaddis 2014). For white women looking to enter customer-facing jobs, the disadvantage that comes from signaling lowbrow versus highbrow cultural taste in a résumé is comparable to the disadvantage that comes from listing a degree from a state university versus a degree from an Ivy League university.

\section{The Survey Experiment}

\section{Data and Methods}

The question I consider next is what leads employers to discriminate on the basis of cultural taste at the point of hire. Hypotheses 3 through 5 offer three possible explanations: perceptions of competence, perceptions of polish, and perceptions of warmth. To test these hypotheses and identify the social-psychological mechanisms through which cultural signals of class influence employers' hiring evaluations, I distributed a web-based survey experiment to a nationwide sample of 1,428 hiring 
25

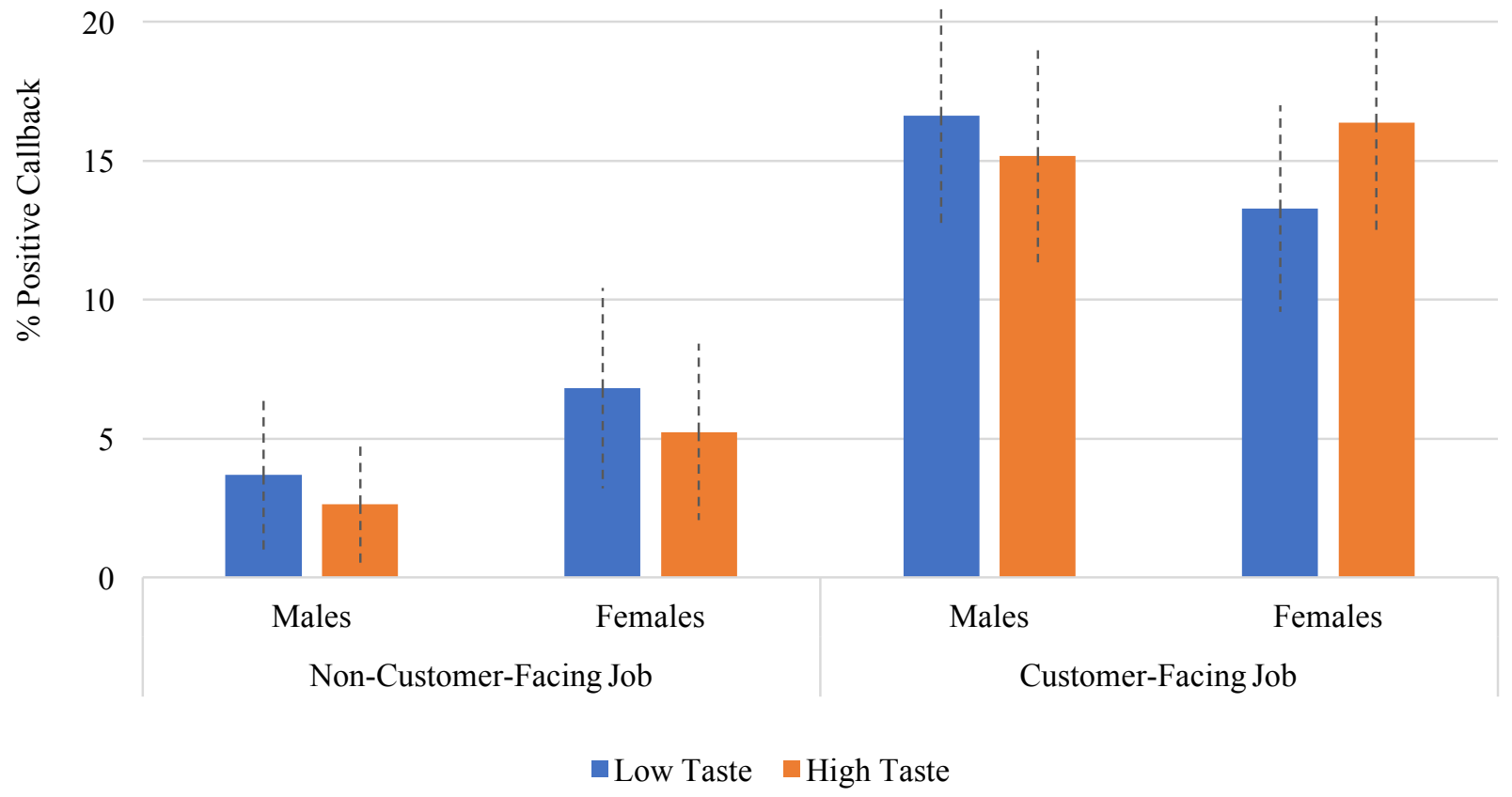

Figure 2: Effect of signals of cultural taste on rates of positive callback. Dashed lines represent confidence intervals. 
Table 4: Demographic characteristics of survey experiment sample.

\begin{tabular}{|c|c|}
\hline Individual Respondent Characteristics & $\mathrm{N}=1,428$ \\
\hline Female (\%) & 64.05 \\
\hline White $(\%)$ & 86.62 \\
\hline B.A. or more $(\%)$ & 71.55 \\
\hline Self-identified class (median) & Upper-middle \\
\hline \multicolumn{2}{|l|}{ Age $(\%)$} \\
\hline $18-34$ & 11.84 \\
\hline $35-59$ & 66.15 \\
\hline $60+$ & 22 \\
\hline Job tenure (median) & 13 years \\
\hline \multicolumn{2}{|l|}{ Respondent Firm Characteristics } \\
\hline \multicolumn{2}{|l|}{$\overline{\text { Industry }(\%)}$} \\
\hline Accommodation, food services & 1.54 \\
\hline Administrative, support & 2.87 \\
\hline Agriculture, forestry, food & 0.63 \\
\hline Arts, entertainment, recreation & 2.66 \\
\hline Construction & 1.75 \\
\hline Education & 13.38 \\
\hline Finance, insurance & 5.96 \\
\hline Government, public administration & 13.31 \\
\hline Healthcare, social assistance & 8.2 \\
\hline Information & 2.1 \\
\hline Management of companies & 1.12 \\
\hline Manufacturing & 8.97 \\
\hline Mining & 0.14 \\
\hline Professional, scientific, technical services & 9.95 \\
\hline Real estate, rental, leasing & 0.91 \\
\hline Retail & 6.45 \\
\hline Transportation, warehousing & 2.24 \\
\hline Utilities & 1.26 \\
\hline Waste management, remediation & 0.07 \\
\hline Wholesale & 1.96 \\
\hline Other & 14.5 \\
\hline \multicolumn{2}{|l|}{ Type of Firm (\%) } \\
\hline Private, for profit & 59.15 \\
\hline Private, nonprofit & 14.58 \\
\hline Local government & 6.73 \\
\hline State government & 12.89 \\
\hline Federal government & 4.48 \\
\hline Self-employed, family business & 2.17 \\
\hline \multicolumn{2}{|l|}{ Number of Employees (\%) } \\
\hline $1-99$ & 31.6 \\
\hline 100-999 & 29.86 \\
\hline 1,000 or more & 38.54 \\
\hline
\end{tabular}

Note: B.A., Bachelor of Arts.

ment consisted of a $2 \times 2 \times 2 \times 2$ mixed factorial design with one within-subjects factor (applicant cultural taste) and three between-subjects factors (applicant gender, job type, and firm status). As in the audit study, applicant cultural taste varied within subjects, as each respondent received two résumés that differed in their 
signals of cultural taste. Applicant gender, job type, and firm status varied between subjects, as these characteristics were randomly assigned to résumé pairs and thus varied between respondents. The effects of cultural taste, job type, and applicant gender are analyzed in this article; firm status is not analyzed. For greater detail on the survey-experimental design, see the online supplement.

The survey experiment was web based and distributed to a nationwide sample of 1,428 hiring managers drawn from a preexisting panel of human resources and/or personnel services managers maintained by the research company Research Now. Research Now panel members are recruited through web-based programs (e.g., web banners and corporate email campaigns) that offer a variety of incentives in exchange for participation in a panel. Respondents were offered an honorarium of $\$ 4.00$ in e-Rewards currency upon completion of the survey.

At the beginning of the survey, respondents were asked to evaluate two applicants seeking an entry-level position at a hotel. Each respondent was randomly assigned to one of eight possible hiring conditions: (1) the hiring organization was either high in status ("The Ritz-Carlton Hotel") or low in status ("Super 8 Motel") $^{5}$, (2) the hiring occupation was either high in customer contact (customer service representative) or low in customer contact (accounting clerk) ${ }^{6}$, and (3) the gender of the two applicants was either male or female.

Respondents were then provided with two résumés and asked to respond to a series of questions about the employability and recommended job placement of each applicant. They were also asked to rate each applicant on a series of characteristics related to competence, warmth, and polish. The order in which the résumés were shown and the résumé formats that were used were randomized and counterbalanced.

Likelihood of interview measure. Respondents were asked to rate, on a five-point Likert-type scale ( $1=$ not at all; $5=$ extremely), their responses to the following question: "How likely would you be to recommend this applicant for an interview?"

Competence measure. Respondents were asked to rate, on a five-point Likert scale $(1=$ not at all; $5=$ a great deal), to what extent they feel the following traits are characteristic of the applicant: capable, competent, efficient, intelligent, and organized (Correll et al. 2007; Fiske et al. 2002). Mean competence ratings were developed based on this competence scale (mean: 3.43; SD: 0.62; alpha: 0.93).

Polish measure. Respondents were asked to rate, on a five-point Likert scale $(1=$ not at all; $5=$ a great deal $)$, to what extent they feel the following traits are characteristic of the applicant: articulate, polished, professional, and sophisticated. Mean polish ratings were developed based on this scale (mean: 3.21; SD: 0.68; alpha: 0.89).

Warmth measure. Respondents were asked to rate, on a five-point Likert scale $(1=$ not at all; $5=$ a great deal), to what extent they feel the following traits are characteristic of the applicant: friendly, good natured, tolerant, trustworthy, warm, and sincere (Correll et al. 2007; Fiske et al. 2002;). Mean warmth ratings were developed based on this scale (mean: 3.35; SD: 0.63; alpha: 0.92). 


\section{Empirical Strategy}

The following analyses explore how cultural signals of class influence employers' perception and evaluation of job applicants. I first examine the effect of cultural signals of class on respondents' expressed likelihood of recommending each applicant for an interview. I then examine the effect of these signals on respondents' ratings of competence, polish, and warmth. To measure these effects, I created difference scores for the four dependent variables: likelihood of interview, perceived competence, perceived polish, and perceived warmth. I subtracted survey responses to the résumés signaling lowbrow tastes from survey responses to the résumés signaling highbrow tastes. These difference scores capture the differential effect that signaling highbrow versus lowbrow taste in a résumé has on each dependent variable.

In the analyses detailed below, I conduct paired t-tests to measure the statistical significance of these effects. I then conduct analyses of variance to analyze how these effects vary according to the two between-subjects factors: applicant gender and job type. First, I conduct a $2 \times 2$ analysis of variance to analyze the effect of the between-subjects factors on difference scores for the main outcome variable: likelihood of interview. Secondly, I conduct a 2 X 2 multivariate analysis of variance (MANOVA) to analyze the effect of the between-subjects factors on difference scores for the three mechanisms altogether: perceptions of competence, polish, and warmth. The results of these analyses of variance are summarized below. Thirdly, I examine the extent to which ratings of competence, polish, and warmth mediate the effect of signals of cultural taste on likelihood-of-interview ratings. Difference scores are not used in this mediation analysis. Instead, I include cultural taste as a predictor, and I run linear random-effects models using Hicks and Tingley's (2011) formal mediation analysis technique.

\section{Main Analysis}

A paired t-test confirms that across hiring conditions, hiring managers in the survey experiment report a statistically significant greater interest in interviewing applicants with highbrow cultural tastes than applicants with lowbrow cultural tastes. The average difference in likelihood-of-interview ratings for applicants with highbrow versus lowbrow cultural tastes is small but statistically significant (difference $=0.05 ; p<0.05){ }^{7}$

As in the audit study, the effect of these cultural signals of class appears to be driven by the survey responses of hiring managers assigned to the customer-facing hiring position. Figure 3 presents the mean values of likelihood of interview for male and female applicants with highbrow and lowbrow cultural tastes in the two job conditions: customer service representative and accounting clerk. I find that applicants with highbrow tastes receive a higher likelihood-of-interview rating than applicants with lowbrow tastes when the hiring position is customer facing $(\mathrm{F}[1,1425]=2.83 ; p<0.10)$. This result is not statistically significant at a threshold of $p<0.05$, but it is consistent with what I observe in the audit study: for customerfacing jobs, more so than non-customer-facing jobs, hiring managers express a greater interest in interviewing applicants with highbrow tastes. 
3.7

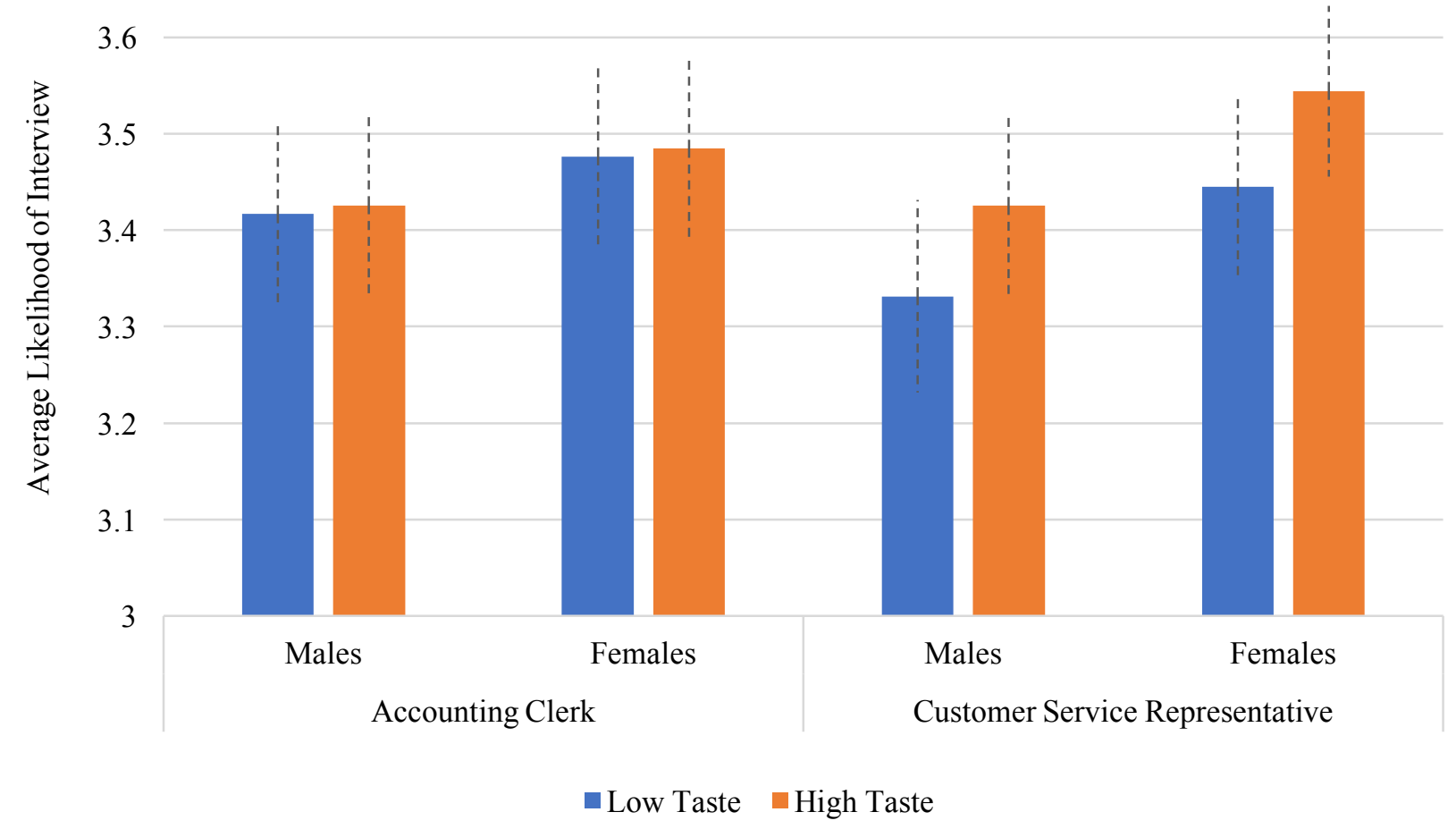

Figure 3: Effect of signals of cultural taste on likelihood-of-interview ratings. Dashed lines represent confidence intervals.

I do not find that the effect of cultural taste on likelihood-of-interview ratings varies in a meaningful way by applicant gender. In their evaluation of customerfacing women as well as customer-facing men, hiring managers report a greater likelihood of recommending applicants with highbrow cultural tastes for an interview. This pattern in employers' hiring attitudes contrasts with the patterns I observed in the audit study, in which only women applying to customer-facing jobs faced discrimination on the basis of cultural taste. The question I consider next is why hiring managers express this general preference for both male and female applicants with highbrow cultural tastes.

I hypothesized that cultural signals of class would affect hiring evaluations largely because they bias perceptions of characteristics such as competence, polish, and/or warmth. In Figure 4, I plot mean values for the perceived competence, polish, and warmth of male and female applicants across the hiring conditions. I test the significance of these differences in means using paired t-tests.

I find that signals of highbrow taste have a significantly more positive effect than signals of lowbrow taste on perceptions of competence (difference $=0.05 ; p<0.01$ ) and perceptions of polish (difference $=0.15 ; p<0.01$ ). I also find that perceptions of competence and polish are highly correlated, with a Pearson's correlation coefficient of 0.83 . So, for both men and women, an applicant with lowbrow cultural tastes is 
3.6

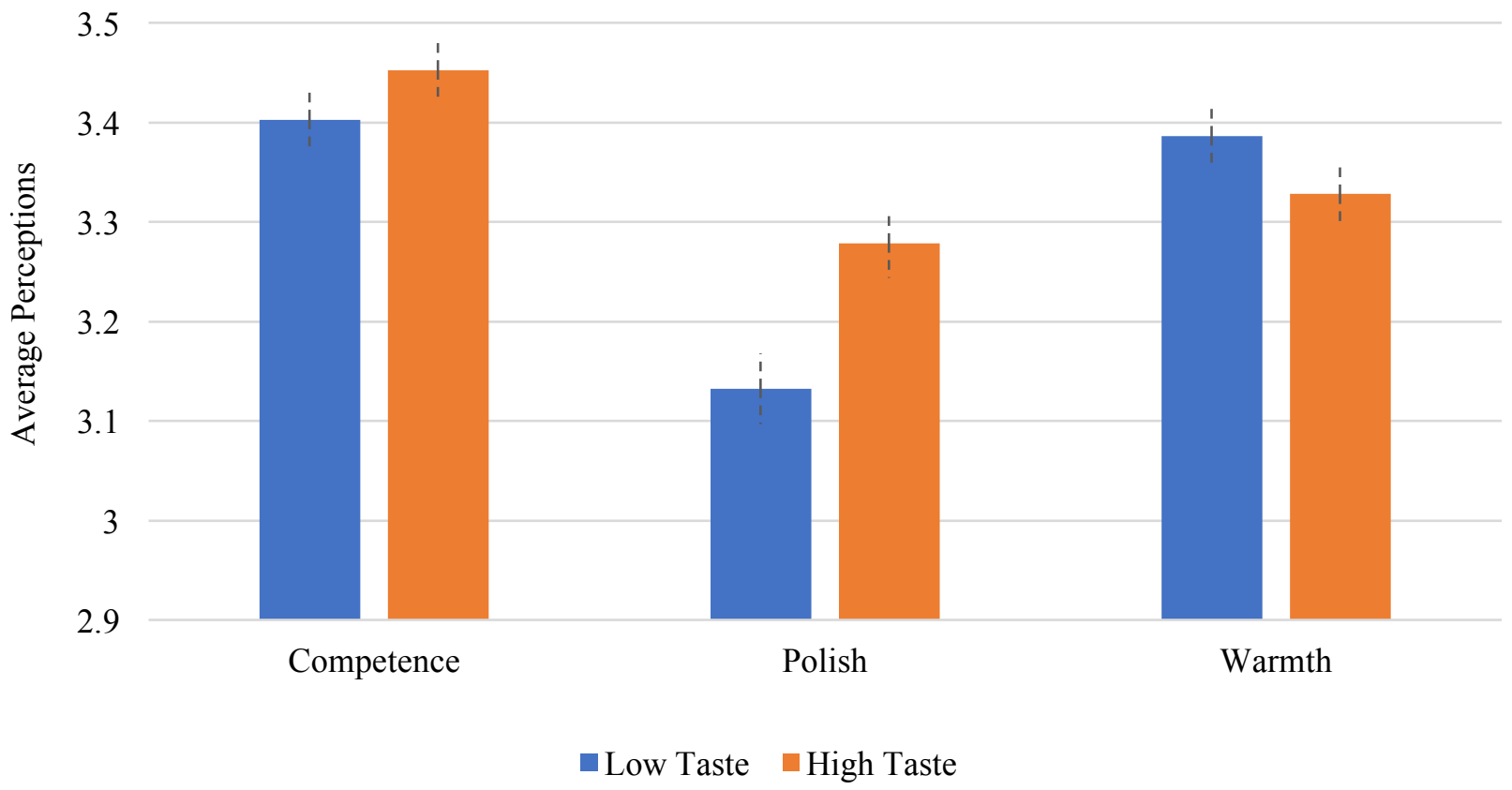

Figure 4: Effect of signals of cultural taste on perceptions of competence, polish, and warmth. Dashed lines represent confidence intervals.

perceived not only as significantly less refined but as significantly less capable of performing routine work tasks than an applicant with highbrow cultural tastes.

Around ratings of warmth, however, signals of highbrow cultural taste do not maintain this positive effect. Hiring managers may expect highbrow workers to be more competent and refined than their lowbrow peers, but they do not expect them to be more likable. In fact, they perceive them as less likable, attributing statistically significantly lower levels of warmth to applicants with highbrow tastes than to applicants with lowbrow tastes (difference $=-0.06 ; p<0.01$ ). A 2 X 2 MANOVA confirms that the differential effect of highbrow versus lowbrow cultural taste on perceptions of competence, polish, and warmth does not vary significantly by applicant gender or job type.

Ultimately, it appears that applicants with highbrow cultural tastes are the most respected of their peers, but they are not the most liked, a phenomenon that has been well documented in the social psychological literature (Fiske et al. 2002; Judd et al. 2005). Studies show that a higher perceived status and greater perceived competence often come at the cost of one's perceived warmth (Judd et al. 2005). More recently, this phenomenon has been documented by Hahl and Zuckerman (2014), who find that high-status actors tend to be attributed lower levels of authenticity than low-status actors.

That said, hiring managers' affinity for applicants with lowbrow tastes also appears to be driven by a shared cultural background. At the end of the survey, 
I asked respondents to rate, on a scale of 1 to $3(1=$ dislike, $2=$ neither like nor dislike, and $3=$ like), their preferences for the various cultural signals included in the résumés. The lowbrow cultural signals included bowling, bluegrass music, and barbecuing. To develop a measure of respondents' average taste for lowbrow culture, I added their ratings for each of these signals and divided by three. The highbrow signals included tennis, classical music, jazz, and gourmet cooking. To develop a measure of respondents' average taste for highbrow culture, I added their ratings for each of these signals and divided by four. Respondents' average rating of lowbrow cultural signals was 2.35 (more positive than neutral). Similarly, their average rating of highbrow cultural signals was 2.33 . Thus, the majority of respondents were omnivorous in their tastes, expressing either a tolerance or a preference for both highbrow and lowbrow culture.

In Table 5, I estimate the extent to which respondents' own tastes for lowbrow or highbrow culture might be influencing the level of warmth they attribute to applicants with lowbrow or highbrow tastes. As expected, Model 1 reports that respondents perceive applicants with highbrow tastes as less warm than applicants with lowbrow tastes. Models 2 and 3 then measure the interaction of applicant taste with respondent taste to determine if respondents' own cultural tastes influenced these perceptions. The statistically significant, negative interaction term (coefficient $=-0.12 ; p<0.05$ ) reported in Model 2 indicates that the greater a respondent's selfreported taste for lowbrow culture is, the less warmth that respondent is likely to attribute to an applicant with highbrow tastes relative to an applicant with lowbrow tastes. On the other hand, the small and nonsignificant interaction term (coefficient $=0.03$; not significant) reported in Model 3 indicates that attributions of warmth do not vary systematically according to respondents' tastes for highbrow culture. I conclude that applicants with highbrow tastes are attributed lower levels of warmth than applicants with lowbrow tastes largely because the majority of respondents in the sample hold favorable attitudes toward lowbrow culture.

Only a small percentage of respondents-less than 2 percent- report a dislike for all lowbrow cultural activities, and I find that these respondents do attribute lower levels of warmth to applicants with lowbrow tastes than to applicants with highbrow tastes. In Model 2, this is denoted by the positive and statistically significant coefficient of 0.22 observed for applicants with highbrow cultural tastes. Altogether, these findings suggest that it is probable, but not inevitable, that applicants with highbrow tastes will be attributed lower levels of warmth than applicants with lowbrow tastes, as attributions of warmth appear to vary according to the personal tastes of employers. This phenomenon is probable, especially in nonelite labor markets, because lowbrow cultural preferences are common and known to characterize both elite and nonelite Americans. It is not inevitable, however, because in exceptionally elite contexts in which employers with exclusively highbrow tastes may be more prevalent or in contexts in which the majority of hiring managers feel ambivalent toward lowbrow culture, my findings suggest that applicants with highbrow cultural tastes will be attributed equal if not greater levels of warmth than applicants with lowbrow cultural tastes. 
Table 5: Ordinary least squares regression measuring the effect of applicant cultural taste, interacted with respondent cultural taste, on perceptions of warmth.

\begin{tabular}{|c|c|c|c|}
\hline & (1) & (2) & (3) \\
\hline Applicant Highbrow Taste & $\begin{array}{r}-0.06^{\dagger} \\
(0.02)\end{array}$ & $\begin{array}{c}0.22^{+} \\
(0.09)\end{array}$ & $\begin{array}{c}-0.14 \\
(0.09)\end{array}$ \\
\hline Respondent Lowbrow Taste & & $\begin{array}{c}0.16^{\dagger} \\
(0.04)\end{array}$ & \\
\hline App High Taste X Resp Low Taste & & $\begin{array}{r}-0.12^{+} \\
(0.04)\end{array}$ & \\
\hline Respondent Highbrow Taste & & & $\begin{array}{c}0.07 \\
(0.04)\end{array}$ \\
\hline App High Taste X Resp High Taste & & & $\begin{array}{c}0.03 \\
(0.04)\end{array}$ \\
\hline Constant & $\begin{array}{c}3.387^{+} \\
(0.017)\end{array}$ & $\begin{array}{c}3.016^{\dagger} \\
(0.097)\end{array}$ & $\begin{array}{r}3.224^{+} \\
(0.099)\end{array}$ \\
\hline R-squared & 0.002 & 0.008 & 0.006 \\
\hline
\end{tabular}

Notes: Standard errors (in parentheses) are clustered by respondent identity. Two-tailed tests were used for significance. App, applicant; Resp, respondent.

${ }^{*} p<0.10,{ }^{+} p<0.05$.

\section{Mediation Analysis}

To what extent can these ratings of competence, polish, and warmth help to explain the positive effect of signals of highbrow taste on respondents' likelihoodof-interview ratings? Table 6 presents results from a formal mediation analysis using an estimation technique developed by Hicks and Tingley (2011). Hicks and Tingley's method does not support the use of ordered logistic regression models for multilevel data, so I use a linear random-effects model in this analysis with a random intercept included for the respondent. Using this method, I measure the mediated and direct effects of signals of cultural taste on respondents' likelihood-ofinterview ratings. If ratings of competence, polish, and/or warmth play a significant role in mediating the effect of cultural taste on ratings of interview likelihood, I should find that they account for a statistically significant proportion of the total effect of cultural taste.

According to Model 1 in Table 6, the total effect of highbrow, versus lowbrow, cultural taste on likelihood-of-interview ratings is statistically significant and positive, at a value of 0.05 . Eighty-two percent of this total effect is mediated by perceptions of competence, an indication that perceptions of competence are an important mediator of the effect of cultural taste on likelihood-of-interview ratings. Hiring managers express a greater interest in interviewing applicants with highbrow cultural tastes because they perceive them to be more competent than applicants with lowbrow cultural tastes.

Perceptions of polish, however, appear to be an even more powerful explanatory variable here. In Model 2, I find that the proportion of the total effect of highbrow taste that is mediated by perceptions of polish is more than double the proportion of the total effect mediated by perceptions of competence, at a value of 201 percent. 
Table 6: Average marginal effect of signals of highbrow taste on likelihood of interview mediated by perceptions of competence, polish, and warmth.

\begin{tabular}{lccc}
\hline $\begin{array}{l}\text { Mediator: } \\
\text { Covariate: }\end{array}$ & $\begin{array}{c}(1) \\
\text { Perceived Competence }\end{array}$ & $\begin{array}{c}(2) \\
\text { Perceived Polish }\end{array}$ & $\begin{array}{c}(3) \\
\text { Perceived Warmth } \\
\text { Perceived Polish }\end{array}$ \\
\hline Total Effect of Highbrow Taste & $0.05^{+}$ & $0.05^{\dagger}$ & $-0.06^{\dagger}$ \\
& $(0.01$ to 0.11$)$ & $(0.01$ to 0.11$)$ & $(-0.10$ to -0.02$)$ \\
Average Mediated Effect & $0.05^{\dagger}$ & $0.11^{\dagger}$ & $-0.04^{\dagger}$ \\
Direct Effect of Highbrow Taste & $(0.02$ to 0.08$)$ & $(0.08$ to 0.14$)$ & $(-0.05$ to -0.03$)$ \\
Proportion of Total Effect Mediated & 0.01 & $-0.06^{\dagger}$ & -0.02 \\
& $(-0.03$ to 0.05$)$ & $(-0.10$ to -0.01$)$ & $(-0.06$ to 0.03$)$ \\
& $0.82^{\dagger}$ & $2.01^{\dagger}$ & $0.72^{\dagger}$ \\
\hline
\end{tabular}

Notes: $95 \%$ confidence intervals are in parentheses. Two-tailed tests were used for significance. ${ }^{*} p<0.10,{ }^{+} p<0.05$.

This is a result of the direct effect of highbrow taste being similar in magnitude to the total effect of highbrow taste but opposite in sign, at a value of -0.06 . Altogether, it indicates that perceptions of polish are acting as a suppressor variable in Model 2. The positive effect of highbrow taste on perceptions of polish suppresses the negative direct effect of highbrow taste on likelihood of interview, generating an average mediated effect that is greater than 100 percent. Based on these findings, I conclude that hiring managers' preference for those they perceive as polished leads them to favor applicants with highbrow tastes over those with lowbrow tastes. However, given the negative direct effect observed in Model 2, I would expect hiring managers to favor applicants with lowbrow tastes in a context in which levels of polish are perceived as equal across highbrow and lowbrow applicants.

And why would employers favor lowbrow applicants? Because hiring managers perceive lowbrow applicants as warmer, or more likable. In Model 3, the average effect of cultural taste on perceptions of warmth accounts for 72 percent of the negative effect of cultural taste on likelihood of interview when the suppressive effects of perceived polish are controlled for, reducing the direct effect of cultural taste to a small and nonsignificant value. I conclude that the negative effect of highbrow cultural taste, once perceptions of polish are controlled for, reflects respondents' positive valuation of warmth and their belief that people with lowbrow tastes are more likely to be warm.

\section{The Audit Study Revisited}

How can these survey-experimental findings help us to understand the audit study findings presented earlier? It is first important to note that the audit study and survey experiment are measuring different outcomes. The survey experiment measures employers' perceived preferences-what they believe to be their likelihood of extending an interview invitation to an applicant and why. The audit study 
measures employers' behaviors - their actual likelihood of responding positively to an applicant at the initial point of application. Not unexpectedly, I find that the behaviors displayed by employers in the audit study do not always reflect the preferences expressed by employers in the survey experiment (Pager and Quillian 2005).

For example, in the survey experiment, I find that employers are generally more interested in interviewing applicants with highbrow tastes, regardless of gender, because they expect them be more polished and competent than applicants with lowbrow tastes. I also find that employers' expectations around polish drive a larger part of their interest in highbrow applicants. This may explain why their interest in highbrow applicants also intensifies in customer-facing hiring contexts.

In the audit study, however, I find that cultural signals of class only affect employer responses to women applying to customer-facing jobs. In their response to men, employers' hiring attitudes may indicate a preference for applicants with highbrow tastes, but the behaviors observed in the audit study reflect a willingness to give lowbrow men an opportunity to interview. At the point of application, it is only in their response to female applicants that employers in customer-facing hiring contexts penalize applicants with lowbrow tastes, evidence that, as the Conditional Gender Role Hypothesis predicted, the class-based cultural standards applied to women are more stringent than those applied to men.

\section{Discussion and Conclusion}

The central inquiry of this article is whether the class-based discrimination observed in elite labor markets reflects a more fundamental class bias among Americans employers, one that trickles down to nonelite labor markets as well. To address this question, I examine to what extent and under what conditions cultural signals of class shape the hiring outcomes of job applicants in middle-income labor markets. Results from an audit study of employment discrimination in four U.S. cities reveals that among women applying to customer-facing jobs, those with highbrow cultural tastes (the cultural signals of a higher-class background) experience a higher rate of positive callback than those with lowbrow cultural tastes (the cultural signals of a lower-class background). This phenomenon is driven primarily by differences in the rate at which employers extend formal interview requests to women applying to customer-facing jobs. Meanwhile, signals of cultural taste have no systematic effect on the callback rates of male and/or non-customer-facing job applicants.

Results from a survey-experimental study of 1,428 U.S. hiring managers suggest that these differing patterns of employer callback may be explained by the relatively positive effect of highbrow cultural signals on perceptions of polish and competence and their relatively negative effect on perceptions of warmth. Hiring managers may not like highbrow applicants as much as they like lowbrow applicants, but when expectations of polish are high-as they traditionally have been for female, customer-facing workers-employers are systematically more likely to penalize displays of lowbrow taste and reward displays of highbrow taste.

Overall, this study makes a series of empirical and theoretical contributions to the sociological literature on class, culture, and labor market stratification. For 
one, this study uncovers a hidden form of class bias in the middle-income labor market: employment discrimination on the basis of cultural signals of class. In support of the Conditional Gender Role Hypothesis, this study also reveals cultural signals of class to be consequential in ways that are gendered and customer centric. Employers are more likely to discriminate against lower-class women than lowerclass men and in customer-facing contexts, in which women are more likely to seek work. Customer-oriented positions, such as customer service and sales, are two of the most common occupations for skilled middle-class women, who predominate in service industries (U.S. Department of Labor 2015). Thus, the implication of this article that opportunities for customer-facing work are more accessible to lowerclass men than they are to lower-class women may contribute to our understanding of why social mobility in the U.S. is generally lower for women than it is for men (Beller and Hout 2006; Urahn et al. 2012).

Findings from this study also corroborate and complicate current understandings of the class-based cultural hierarchy in the United States, revealing the hidden value of highbrow taste as a signal of polish and competence as well as its hidden cost as a signal of warmth. When standards of polish are theorized to be high, I show that employers, faced with a diverse pool of applicants, are more sensitive to signals of taste and thus more inclined to discriminate against applicants with lowbrow tastes. When standards of polish are theorized to be lower, however, I show that a pattern more akin to cultural matching emerges, as a greater number of employers respond positively to workers with lowbrow tastes-workers who share their tastes and who we know them to like personally.

There are some limitations to this study that warrant further consideration and research. First, with experimental work, replication is crucial, and it will be important to test the conclusions of this study under differing experimental conditions. The effects I observe in the survey experiment, for instance, were generated under a particular set of hypothetical hiring conditions, and their robustness to hiring scenarios outside of the hotel industry is presumed but unknown.

Furthermore, cultural signals of class include more than just taste. Although the taste-based signals I develop in this study are meaningful and socially consequential, they are still fairly weak markers of social class with fairly weak effects. At the point of application, there are a limited number of ways in which an applicant's class background may be culturally expressed. However, interactional style, accent, speech cadence, style of dress, and bodily comportment are all cultural markers of class with differing gender norms that may be conveyed, if not in a résumé then on a phone screen or in a job interview. Class may be a consequential lens through which employers in the United States evaluate workers, but the labor market outcomes that result may vary according to the class information applicants provide and the class information employers seek. Additionally, it is important to note that the cultural effects I observe in this study reflect only a portion of the effect of social class origin on labor market outcomes. In nonexperimental conditions, differences in cultural taste compound and perhaps interact with a number of other class-based differences among job applicants, including disparities in educational attainment, college selectivity, and work experience. 
Findings from this study also suggest further investigation of the effects of job context on labor market outcomes. For example, job prestige and job feminization are two (correlated) factors that may help to explain why the results of this study stand in stark contrast to the results of Rivera and Tilcsik's (2016) study of class bias in an elite labor market. In the prestigious, male-dominated labor market of law firms, Rivera and Tilcsik observe a significant interaction of gender and class signals, as I do, but they find that it is men rather than women whose labor market outcomes are significantly affected by signals of class.

This difference in findings may be attributable to important differences in the labor markets under investigation in Rivera and Tilcsik's study and my own. Compared to employers in the more feminized, middle-income labor markets of customer service and sales (examined here), employers in law firms may draw more heavily on class signals to distinguish between male applicants because the applicant pools are more likely to be dominated by men. Furthermore, the demands of high-income jobs, such as law, may raise commitment standards for women in ways that less prestigious and more feminized jobs do not, drowning out distinguishing characteristics such as class. Given how central applicant gender appears to be to the study of class bias in U.S. employment, it will be important to investigate more systematically how the effects of gender and class markers interact in job contexts that vary in their degree of feminization and prestige. Although job prestige may not dictate whether class signals matter at the point of hire, it does appear to dictate how class signals matter.

Lastly, firm prestige is a potential moderating factor that goes unexplored in this study. An audit study of how signals of class shape labor market outcomes in an industry in which the statuses of organizations are well documented and widely agreed upon would provide this additional insight, allowing us to test whether the employment discrimination I observe in customer-facing hiring contexts is in fact more prevalent in high-status firms than in low-status firms.

These limitations aside, however, the survey and audit study findings presented in this article offer unique insight into the cultural content of American class bias and the gendered nature of its labor market consequences. Bourdieu (1986) once referred to cultural background and taste as "no doubt the best hidden form" of the hereditary transmission of class advantage in institutions. Indeed, I find that cultural signals of class systematically pattern the evaluation and selection of American workers for middle-class jobs and to the disadvantage of women.

\section{Notes}

1 It is important to note that the classification of some tastes as high status and others as low status is not the inevitable outcome of inherent differences in the quality or value of these cultural forms (Bourdieu 1984; DiMaggio 1982b). According to DiMaggio's (1982b) historical analysis of nineteenth-century Boston, such status distinctions were rarely made in the United States before 1850. Instead, high-status culture was institutionalized by Boston elites in an effort to legitimate their authority and class position over a growing population of working-class Irish immigrants (DiMaggio 1982b). Thus, status-based 
cultural differences are not only meaningful indicators of social class differences but in fact emerged during periods of elite class formation and social closure.

2 Survey data confirm that the cultural tastes I use to signal a higher-class position are more exclusive to the class-advantaged than the cultural tastes I use to signal a lowerclass position. According to the 2012 Survey of Public Participation in the Arts, the gap between college-educated and non-college-educated respondents in taste for classical and jazz music is greater than the gap in taste for country and bluegrass music. There are limited fine-grained data on the relationship between social class and sports participation. However, according to the 2014 American Time Use Survey, educational background is negatively correlated with going bowling and positively correlated with playing tennis. There are no fine-grained data, to my knowledge, on class differences in taste for barbecue and gourmet food.

3 According the 2012 Survey of Public Participation in the Arts, the correlation between a preference for classical music and jazz music is 0.42 . The correlation between a preference for country music and bluegrass music is 0.33 .

4 Wording varied across the two résumé templates. For example, Template 1 contained the following as one of several bullet points under the description of the applicant's current job: "Facilitate daily sales transactions with customers and vendors." In Template 2, a similar bullet point was included, but it was rewritten as follows: "Communicate with vendors and assist in sales." The two templates also varied in font and formatting. For example, Template 1 included the Times New Roman font and listed time intervals for each position in a column on the right-hand side of the document, whereas Template 2 included the Cambria font and listed time intervals for each position in a column on the left-hand side of the document. Pilot studies were conducted on Mechanical Turk to confirm that the two formats did not differentially influence the perception of applicants.

5 Manipulation checks included in the survey confirm that respondents perceived the Super 8 as a hotel with low prestige and The Ritz-Carlton as a hotel with high prestige. On a prestige scale ranging from 1 to 3 , the Super 8 received a score of 1.13 , and The Ritz-Carlton received a score of 2.85 .

6 According to the Bureau of Labor Statistics, customer service representative and accounting clerk are two of the most common occupations in the United States. Additionally, according to the Occupational Information Network $\left(\mathrm{O}^{*} \mathrm{Net}\right)$, these occupations differ substantially in the average levels of social interaction they require. $\mathrm{O}^{*} \mathrm{Net}$ classifies the occupation of accounting clerk as conventional and enterprising, whereas it classifies the occupation of customer service representative as conventional, enterprising, and social.

7 Given the popularity of country music in the South and its centrality to this study as a signal of lowbrow taste, it is plausible that the lowbrow cultural signals used in this study had a weaker effect on hiring evaluations in the South because they were weaker class differentiators. To test for this in my survey experimental findings, I looked for regional variation in the effect of signals of cultural taste on likelihood-of-interview ratings. I find that even in the South, signals of highbrow taste have a more positive effect on hiring evaluations than signals of lowbrow taste. That said, the effect of highbrow taste appears to be weaker in the South than it is in other regions. This difference is not statistically significant, but it suggests that country music may be a more ambiguous class signal in the South than in other regions and that signals of cultural taste shape hiring evaluations to the extent that they are meaningful class differentiators. 


\section{References}

Ai, Chunrong, and Edward C. Norton. 2003. "Interaction Terms in Logit and Probit Models." Economics Letters 80:123-9. https://doi .org/10.1016/S0165-1765(03)00032-6.

Aschaffenburg, Karen, and Ineke Maas. 1997. "Cultural and Educational Careers: The Dynamics of Social Reproduction." American Sociological Review 62:573-87. https://doi . org/10.2307/2657427.

Beller, Emily, and Michael Hout. 2006. "Intergenerational Social Mobility: The United States in Comparative Perspective." Future of Children 16:19-36. https://doi .org/10.1353/ foc. 2006.0012.

Bertrand, Marianne, and Sendhil Mullainathan. 2004. "Are Emily and Greg More Employable Than Lakisha and Jamal? A Field Experiment on Labor Market Discrimination." American Economic Review 94:991-1013. https ://doi .org/10.1257/0002828042002561.

Bourdieu, Pierre. 1973. “Culture Reproduction and Social Reproduction." Pp. 71-112 in Knowledge, Education and Cultural Change, edited by J. Richardson. Westport, CT: Greenwood Press.

Bourdieu, Pierre. 1984. Distinction: A Social Critique of the Judgment of Taste. Cambridge, MA: Harvard University Press.

Bourdieu, Pierre. 1986. “The Forms of Capital." Pp. 241-58 in Handbook of Theory and Research for the Sociology of Education, edited by R. Brown. London, UK: Tavistock.

Bourdieu, Pierre. 1990. The Logic of Practice. Palo Alto, CA: Stanford University.

Bryson, Bethany. 1996. "'Anything but Heavy Metal': Symbolic Exclusion and Musical Dislikes." American Sociological Review 61:884-99. https : //doi .org/10. 2307/2096459.

Christin, Angèle. 2012. "Gender and Highbrow Cultural Participation in the United States." Poetics 40:423-43. https: //doi.org/10.1016/j.poetic.2012.07.003.

Coleman, Richard, and Bernice Neugarten. 1971. Social Status in the City. San Francisco, CA: Jossey-Bass, Inc.

Coleman, Richard, Lee Rainwater, and Kent McClelland. 1978. Social Standing in America: New Dimensions of Class. New York, NY: Basic Books.

Collins, Randall. 1971. "Functional and Conflict Theories of Educational Stratification." American Sociological Review 36:1002-19. https ://doi .org/10. 2307/2093761.

Collins, Randall. 1974. "Where Are Educational Requirements for Employment Highest?" Sociology of Education 47:419-42. https ://doi .org/10.2307/2112213.

Collins, Randall. 1988. "Women and Men in the Class Structure." Journal of Family Issues 9:27-50. https://doi .org/10.1177/019251388009001003.

Collins, Randall. 1992. "Women and the Production of Status Cultures." Pp. 152-86 in Cultivating Differences: Symbolic Boundaries and the Making of Inequality, edited by M. Lamont and M. Fournier. Chicago, IL: University of Chicago Press.

Correll, Shelley, Stephen Benard, and In Paik. 2007. “Getting a Job: Is There a Motherhood Penalty?" American Journal of Sociology 112:1297-338. https: //doi .org/10.1086/ 511799.

Cuddy, Amy, Susan T. Fiske, and Peter Glick. 2007. "The BIAS Map: Behaviors from Intergroup Affect and Stereotypes." Journal of Personality and Social Psychology 92:631-48. https://doi .org/10.1037/0022-3514.92.4.631.

Devine, Fiona. 1998. "Class Analysis and the Stability of Class Relations." Sociology 32:23-42. https://doi.org/10.1177/0038038598032001003. 
Devine, Fiona. 2004. Class Practices: How Parents Help Their Children Get Good Jobs. Cambridge, UK: Cambridge University Press. https://doi .org/10.1017/CB09780511488771.

DiMaggio, Paul. 1982a. "Cultural Capital and School Success: The Impact of Status Culture Participation on the Grades of U.S. High School Students." American Sociological Review 47:189-201. https://doi.org/10.2307/2094962.

DiMaggio, Paul. 1982b. "Cultural Entrepreneurship in Nineteenth-Century Boston: The Creation of an Organizational Base for High Culture in America." Media, Culture and Society 4:33-50. https: //doi .org/10.1177/016344378200400104.

DiMaggio, Paul. 2012. "Sociological Perspectives on the Face-to-Face Enactment of Class Distinction." Pp. 15-38 in Facing Social Class: How Societal Rank Influences Interaction, edited by S. T. Fiske and H. R. Markus. New York, NY: Russell Sage Foundation.

DiMaggio, Paul, and John Mohr. 1985. “Cultural Capital, Educational Attainment, and Marital Selection." American Journal of Sociology 90:1231-61. https://doi .org/10. 1086/ 228209.

DiMaggio, Paul, and Michael Useem. 1978. "Social Class and Arts Consumption." Theory and Society 5:141-61. https://doi .org/10.1007/BF01702159.

DiMaggio, Paul, and Toqir Mukhtar. 2004. "Arts Participation as Cultural Capital in the United States, 1982-2002: Signs of Decline?" Poetics 32:169-94. https://doi.org/10. $1016 / j$.poetic. 2004.02 .005 .

Douglas, Ann. 1977. The Feminization of American Culture. New York, NY: Knopf.

Dumais, Susan. 2002. "Cultural Capital, Gender, and School Success: The Role of Habitus." Sociology of Education 75:44-68. https : //doi .org/10.2307/3090253.

Erikson, Robert, and John H. Goldthorpe. 1992. The Constant Flux: A Study of Class Mobility in Industrial Societies. Oxford, UK: Clarendon Press.

Farkas, George. 1996. Human Capital or Cultural Capital? Ethnicity and Poverty Groups in an Urban School District. New York, NY: Aldine De Gruyter.

Fiske, Susan T., Amy J. Cuddy, Peter Glick, and Jun Xu. 2002. “A Model of (Often Mixed) Stereotype Content: Competence and Warmth Respectively Follow from Perceived Status and Competition." Journal of Personality and Social Psychology 82:878-902. https://doi . org/10.1037/0022-3514.82.6.878.

Gaddis, Michael. 2014. "Discrimination in the Credential Society: An Audit Study of Race and College Selectivity in the Labor Market." Social Forces 93:1451-79. https: //doi.org/10.1093/sf/sou111.

Granovetter, Mark. 1974. Getting a Job: A Study of Contacts and Careers. Cambridge, MA: Harvard University Press.

Grusky, David B., and Jesper B. Sorensen. 1998. "Can Class Analysis Be Salvaged?" American Sociological Review 103:1187-234. https://doi.org/10.1086/231351.

Hahl, Oliver, and Ezra W. Zuckerman. 2014. "The Denigration of Heroes? How the Status Attainment Process Shapes Attributions of Considerateness and Authenticity." American Journal of Sociology 120:504-54. https ://doi .org/10.1086/678304.

Hicks, Raymond, and Dustin Tingley. 2011. "Causal Mediation Analysis." The Stata Journal 11:1-5.

Hochschild, Arlie. 1979. The Managed Heart: Commercialization of Human Feeling. Berkeley, CA: University of California Press.

Holt, Douglas. 1997. “Distinction in America? Recovering Bourdieu's Theory of Taste from Its Critics." Poetics 25:931-1020. https ://doi .org/10 .1016/S0304-422X (97) 00010-7. 
Hout, Michael. 2008. "How Class Works: Objective and Subjective Aspects of Class since the 1970s." Pp. 25-64 in Social Class: How Does It Work?, edited by A. Lareau and D. Conley. New York, NY: Russell Sage Foundation.

Jackson, Michelle. 2009. "Disadvantaged through Discrimination? The Role of Employers in Social Stratification." The British Journal of Sociology 60:669-92. https ://doi .org/10. $1111 / \mathrm{j} .1468-4446.2009 .01270 . x$.

Johnston, Josée, and Shyon Baumann. 2007. "Democracy versus Distinction: A Study of Omnivorousness in Gourmet Food Writing." American Journal of Sociology 113:165-204. https://doi.org/10.1086/518923.

Judd, Charles M., Laurie James-Hawkins, Vincent Yzerbyt, and Yoshihisa Kashima. 2005. "Fundamental Dimensions of Social Judgment: Understanding the Relations between Judgments of Competence and Warmth." Journal of Personality and Social Psychology 89:899-913. https://doi.org/10.1037/0022-3514.89.6.899.

Kirschenman, Joleen, and Kathryn M. Neckerman. 1991. “'We'd Love to Hire Them But...': The Meaning of Race for Employers." Pp. 203-35 in The Urban Underclass, edited by C. Jencks and P. E. Peterson. Washington, DC: Brookings Institution Press.

Lamont, Michèle. 1992. Money, Morals, and Manners. Chicago, IL: University of Chicago Press. https://doi.org/10.7208/chicago/9780226922591.001.0001.

Lamont, Michèle, and Annette Lareau. 1988. "Cultural Capital: Allusions, Gaps and Glissandos in Recent Theoretical Developments." Sociological Theory 6:153-68. https: //doi .org/10.2307/202113.

Lareau, Annette. 2003. Unequal Childhoods: Class, Race, and Family Life. Berkeley, CA: University of California Press.

Lewis, George. 2008. "Taste Cultures and Musical Stereotypes: Mirrors of Identity?" Popular Music and Society 19:37-58. https : //doi .org/10.1080/03007769508591580.

Lin, Nan. 1999. "Social Networks and Status Attainment." Annual Review of Sociology 25:467-87. https://doi.org/10.1146/annurev.soc.25.1.467.

Lizardo, Omar. 2006a. "How Cultural Tastes Shape Social Networks." American Sociological Review 71:778-807. https://doi.org/10.1177/000312240607100504.

Lizardo, Omar. 2006b. “The Puzzle of Women's 'Highbrow' Culture Consumption: Integrating Gender and Work into Bourdieu's Class Theory of Taste." Poetics 34:1-23. https://doi.org/10.1016/j.poetic.2005.09.001.

Lizardo, Omar, and Sara Skiles. 2016. “Cultural Objects as Prisms: Perceived Audience Composition of Musical Genres as a Resource for Symbolic Exclusion." Socius: Sociological Research for a Dynamic World 2:1-17. https : //doi.org/10.1177/2378023116641695.

Macdonald, Cameron Lynne, and Carmen Sirianni. 1996. Working in the Service Society. Philadelphia, PA: Temple University Press.

Marx, Karl. [1867] 1978. Capital, Vol. 3. Pp. 439-42 in The Marx-Engels Reader, edited by R. Tucker. New York, NY: W. W. Norton and Company.

Mohr, John, and Paul DiMaggio. 1995. “The Intergenerational Transmission of Cultural Capital." Research in Social Stratification and Mobility 14:169-200.

Moss, Philip, and Charles Tilly. 2001. Stories Employers Tell. New York, NY: Russell Sage Foundation.

Norton, Edward C., Hua Wang, and Chunrong Ai. 2004. "Computing Interaction Effects and Standard Errors in Logit and Probit Models." Stata Journal 4:154-67. 
Ollivier, Michèle. 2008. "Modes of Openness to Cultural Diversity: Humanist, Populist, Practical, and Indifferent." Poetics 36:120-47. https://doi.org/10.1016/j.poetic. 2008.02.005.

Pager, Devah. 2003. "The Market of a Criminal Record." American Journal of Sociology 108:937-75. https://doi.org/10.1086/374403.

Pager, Devah, and Lincoln Quillian. 2005. "Walking the Talk: What Employers Say Versus What They Do." American Sociological Review 70:355-80. https://doi.org/10.1177/ 000312240507000301.

Pager, Devah, Bruce Western, and Bart Bonikowski. 2009. "Discrimination in a Low-Wage Labor Market: A Field Experiment." American Sociological Review 74:777-99. https: //doi.org/10.1177/000312240907400505.

Pedulla, David. 2016. "Penalized or Protected? Gender and the Consequences of Nonstandard and Mismatched Employment Histories." American Sociological Review 81:262-89. https://doi.org/10.1177/0003122416630982.

Peterson, Richard, and Albert Simkus. 1992. "How Musical Tastes Mark Occupational Status Groups." Pp. 152-86 in Cultivating Differences: Symbolic Boundaries and the Making of Inequality, edited by M. Lamont and M. Fournier. Chicago, IL: University of Chicago Press.

Peterson, Richard, and Robert Kern. 1996. "Changing Highbrow Taste: From Snob to Omnivore." American Sociological Review 61:900-7. https : //doi .org/10 . 2307/2096460.

Rivera, Lauren. 2011. “Ivies, Extracurriculars, and Exclusion: Elite Employers' Use of Educational Credentials." Research in Social Stratification and Mobility 29:71-90. https : //doi.org/10.1016/j.rssm.2010.12.001.

Rivera, Lauren. 2012. "Hiring as Cultural Matching: The Case of Elite Professional Service Firms." American Sociological Review 77:999-1022. https://doi.org/10.1177/ 0003122412463213.

Rivera, Lauren. 2015. Pedigree: How Elite Students Get Elite Jobs. Princeton, NJ: Princeton University Press. https://doi .org/10.1515/9781400865895.

Rivera, Lauren, and Andras Tilcsik. 2016. "Class Advantage, Commitment Penalty: The Gendered Effect of Social Class Signals in an Elite Labor Market." American Sociological Review 81:1096-131. https://doi.org/10.1177/0003122416668154.

Rossman, Gabriel, and Richard Peterson. 2015. "The Instability of Omnivorous Cultural Taste over Time." Poetics 1-15. https://doi .org/10.1016/j .poetic.2015.05.004.

Savage, Mike, Fiona Devine, Niall Cunningham, Mark Taylor, Yaojun Li, Johs Hjellbrekke, Brigitte Le Roux, Sam Friedman, and Andrew Miles. 2013. "A New Model of Social Class? Findings from the Great British Class Survey Experiment." Sociology 47:219-50. https://doi.org/10.1177/0038038513481128.

Tepper, Steven J. 2000. "Fiction Reading in America: Explaining the Gender Gap." Poetics 27:255-75. https://doi .org/10.1016/S0304-422X (00)00003-6.

ter Bogt, Tom F. M., Marc J. M. H Delsing, Maarten van Zalk, Peter G. Christenson, and Wim H. J. Meeus. 2011. “Intergenerational Continuity of Taste: Parental and Adolescent Music Preferences." Social Forces 90:297-319. https://doi .org/10.1093/sf/90.1.297.

Treiman, Donald. 1977. Occupational Prestige in Comparative Perspective. New York, NY: Academic Press.

US Department of Labor. 2015. "Most Common Occupations for Women." Retrieved August 11, 2017. https://www.dol.gov/wb/stats/most_common_occupations_for_ women.htm. 
Upright, Craig. 2004. "Social Capital and Cultural Participation: Spousal Influence on Attendance at Arts Events." Poetics 32:129-43. https://doi.org/10.1016/j.poetic. 2004.02.002.

Urahn, Susan, Errin Currier, Dana Elliot, Lauren Wechsler, Denise Wilson, and Daniel Colbert. 2012. "Pursuing the American Dream: Economic Mobility Across Generations." Retrieved January 6, 2013. http://www . pewtrusts .org/ /media/legacy/uploadedfiles/ wwwpewtrustsorg/reports/economic_mobility/pursuingamericandreampdf .pdf.

van Eijck, Koen. 1997. “The Impact of Family Background and Educational Attainment on Cultural Consumption: A Sibling Analysis.” Poetics 25:195-224. https ://doi .org/10. 1016/S0304-422X (97)00017-X.

Veblen, Thornstein. [1899] 1967. The Theory of the Leisure Class. New York, NY: Viking Press.

Warde, Alan, David Wright, and Modesto Gayo-Cal. 2007. “Understanding Cultural Omnivorousness: Or, the Myth of the Cultural Omnivore" Cultural Sociology 1:143-64. https://doi.org/10.1177/1749975507078185.

Weber, Max. [1922] 1958. “Class, Status, Party." Pp. 180-95 in From Max Weber: Essays in Sociology, edited by H. Gerth and C. W. Mills. New York, NY: Oxford University Press.

Weininger, Elliot B., Annette Lareau, and Dalton Conley. 2015. "What Money Doesn't Buy: Class Resources and Children's Participation in Organized Extracurricular Activities." Social Forces 94:479-503. https : //doi .org/10.1093/sf/sov071.

Williams, Christine, and Catherine Connell. 2010. "'Looking Good and Sounding Right:' Aesthetic Labor and Social Inequality in the Retail Industry." Work and Occupations 37:349-77. https://doi .org/10.1177/0730888410373744.

Wright, Erik Olin, ed. 2005. Approaches to Class Analysis. Cambridge, UK: Cambridge University Press. https://doi.org/10.1017/CB09780511488900.

Wright, Erik Olin, Cynthia Costello, David Hachen, and Joey Sprague. 1982. "The American Class Structure." American Sociological Review 47:709-26. https://doi .org/10.2307/ 2095208.

Yodanis, Carrie. 2006. "A Place in Town: Doing Class in a Coffee Shop." Journal of Contemporary Ethnography 35:341-66. https : //doi .org/10.1177/0891241606286818.

Acknowledgements: I would like to thank Paul DiMaggio for his intellectual guidance and support as well as Viviana Zelizer, Devah Pager, Susan Fiske, David Pedulla, Patrick Ishizuka, René Flores, and participants of the University of Michigan's Inequality and Family Working Group for their valuable insights and feedback. This research was supported by the Fahs-Beck Fund for Research and Experimentation, Princeton University's Center for the Study of Social Organization, and an Andrew W. Mellon Foundation/American Council of Learned Societies Dissertation Completion Fellowship.

Kyla Thomas: Center for Economic and Social Research, University of Southern California. E-mail: kylathom@usc.edu. 